\title{
Artificial Intelligence and Intellectual Property Law
}

Swapnil Tripathi ${ }^{*}$ and Chandni Ghatak ${ }^{+}$

\begin{abstract}
Artificial intelligence systems have been gaining widespread momentum in today's progressing techsavvy world. With sophisticated technologies being incorporated in the same, it is only a matter of time these systems start to produce marvelous inventions without human intervention of any kind. This brings forth pertinent questions concerning Intellectual Property Rights, (IPR) for, it challenges not only traditional notions of concepts such as patents and copyrights, but also leads to the emergence of questions related to the regulation of such creations amidst others. This paper seeks to provide insight into the expanding scope of IPR laws and artificial intelligence, along with the inevitable challenges it brings from a worldwide lens on the matter. It also attempts to provide suggestions transcending IPR, and seeks to address questions concerning criminal liability for the content created by such technologies.
\end{abstract}

Keywords: Artificial Intelligence, Copyright Law, Intellectual Property Law, Patent Law, Rights of Artificial Intelligence Systems

* National Law University, Jodhpur, Rajasthan, India; swapnil.tripathi221@gmail.com.

+ National Law University, Jodhpur, Rajasthan, India; chandnighatak26@gmail.com. 


\section{Introduction}

Artificial intelligence (AI) systems are growing at an exponential rate today, with more sophisticated forms of software being incorporated into them. AI enabled systems have transcended from performing simple calculations to producing poetry, art work, and other more complex creative work. This raises the question of whether or not such work can be afforded any special status under Intellectual Property (IP) laws, like any other form of work produced by an identifiable human source which is afforded protection under IP laws. This question unravels many other intricate issues, which through this paper the authors aim to highlight. The first part of the paper explains the concept of AI, followed by the IP discourse with the primary focus being on Copyright Laws and AI. Then the paper goes onto the more deliberative end of the copyright debate in connection with AI solutions and highlights the relation of patent laws with AI systems. The paper concludes by providing recommendations on these issues.

\section{What is Artificial Intelligence?}

Computers, coupled with human intelligence, have advanced to even make decisions on their own. This ability of a computer system to take decisions by itself came to be known as artificial intelligence, in common parlance. The term 'artificial intelligence' was formally coined by Mr. John McCarthy, a computer scientist at a conference in 1956. ${ }^{1}$ According to him, it was the notion of a program, processing and acting on information, such that the result is parallel to how an intelligent person would respond in response to similar input. ${ }^{2}$ It was this reliance and curiosity towards machines that AI projects were developed in a manner which

\footnotetext{
1 Prof. A.Lakshminath\&Dr.MukundSarda, Digital Revolution and Artificial Intelligence- Challenges to Legal Education and Legal Research, CNLU LJ (2) (2011-2012).

2 Raquel Acosta, Artificial Intelligence and Authorship Rights, HARVARD JOURNAL OF LAW AND TECHNOLOGY (Feb. 17, 2012), http:// jolt.law.harvard.edu/digest/copyright/artificial-intelligence-andauthorship-rights.
} 
Tripathi and Ghatak Artificial Intelligence and Intellectual Property Law

allowed for the performance of tasks requiring human-like creativity. ${ }^{3}$

However, a question arose whether the results being rendered by the machine are an outcome of its own intelligence, or algorithms and commands. To tackle the same, Sir Alan Turing proposed a test called the 'Turing test'. 4 The test called for the users to converse with a machine/human in a text only format, and then suggest whether they believed they communicated with a human or a machine. ${ }^{5}$ As per Turing, an AI machine showed intelligence if the responses submitted by the same were indistinguishable from real human responses. While this test worked for a couple of years, its application was restricted only to speech machines and certain quizzing purposes. The World Intellectual Property Organization (WIPO) identified the existence of AI and propounded three categories of AI, i.e., expert systems, perception systems, and natural-language systems. ${ }^{6}$

Expert systems are the programs that solve problems in specialized fields of knowledge, such as, diagnosing medical conditions, recommending treatment, determining geological conditions, to name a few. ${ }^{7}$ These systems are also used for creative purposes such as producing art and other such works. This system gathered legal attention when a computer authored work was denied copyright by the Registrar, on the grounds of indeterminate legal status of works created with the aid of computers. ${ }^{8}$ This is an issue that still remains unresolved in many States. Perception systems

${ }^{3}$ Mireille Bert-JaapKoops, et al., Bridging the Accountability Gap: Rights for New Entities in the Information Society?,11 MINN. J.L. SCI. \& TECH. 497, 549-50 (2010).

4 Alan Turing, Computing Machinery and Intelligence, 59 MiND 236, $433-$ 60 (1950).

${ }^{5} \mathrm{Id}$.

6 A. Johnson-Laird, Neural Networks: The Next Intellectual Property Nightmare?, 7 THE COMPUTER LAWYER 14 (March 1990).

${ }^{7}$ Id.

8 Annemarie Bridy, Coding Creativity: Copyright and the Artificially Intelligent Author, STAN. TECH. L. RE. 5(26, 2012), https:// web.law.columbia.edu/sites/default/files/microsites/kernochan/09.mat erials-Bridy.pdf. 
are the systems that allow a computer to perceive the world with the sense of sight and hearing. This is used by topologists, wordcontext experts, etc. ${ }^{9}$ Lastly, a natural language program is meant to understand the meanings of words, requiring a dictionary database. What is noteworthy is, the system takes into consideration different grammatical and textual contexts, to provide a semantic analysis. ${ }^{10}$ The use of these AI systems became so prevalent that, people wanted to procure protection on the outputs. However, the 1956 denial of copyright to a literary work, gave very bleak hopes to these aspirants. But, the debate did not die down, and even reached national courts on grounds of its relevance to the field of IP, namely copyrights and patents.

\section{Copyright and Artificial Intelligence}

Copyright is an integral part of intellectual property rights. It is a legal right granted to the creator of an original work, allowing him/her exclusive rights for its use and distribution. The rationale and justification behind this was the notion that the author is an originator merged with Locke's economic theory of possessive individualism. ${ }^{11}$ Generally, for a grant of a copyright, fulfillment of two essential features is required. Firstly, the work should be in a tangible form, and secondly, it should be original.

A copyright is exercised generally for literary and artistic works. Since one of the contemporary areas of $\mathrm{AI}^{\prime}$ s applicability is creation of literary works, the study of copyright in light of AIs, becomes relevant. The understanding of the same for the purpose of this paper can be achieved by analyzing three judgments -Burrow Gilles Lithographic Co. v.Sarony12, Bleistein v. Donaldson Lithographing 13 and Alfred Bell \& Co. v.Catalda Fine Arts ${ }^{14}$.

\footnotetext{
9 R. KurzWeil, The Age OF Intelligent Machines, 272- 275 (MIT Press: 1990).

$10 \mathrm{Id}$.

11 Leenheer Zimmerman, It's an Original!(?): In Pursuit of Copyright's Elusive Essence, 28 COLM. J. L. \& ARTS 187, 194 (2005).

12 Burrow Gilles Lithographic Co. v. Sarony, 111 U.S. 53 (1884).

${ }^{13}$ Bleistein v. Donaldson Lithographing, 188 U.S. 239 (1903).

14 Alfred Bell \& Co. v. Catalda Fine Arts, 191 F.2d 99 (2d Cir. 1951).
} 
Tripathi and Ghatak Artificial Intelligence and Intellectual Property Law

\section{1 Burrow Gilles Lithographic Co. v. Sarony}

This case revolved around whether a copyright protection can be granted to a photograph. ${ }^{15}$ It was a relevant case because it addressed the dichotomy between creative and mechanical labour. The Court discussed the possibility of granting copyright protection to a product which is the output of a machine. The Court, by holding that purely mechanical labour is per se not creative, narrowed the scope of their protection. ${ }^{16}$ Therefore, if a strict approach like this were to be applied to AI systems, granting copyright for works created by them, would be difficult.

\section{2 Bleistein v. Donaldson Lithographing Co.}

This case was a continuation of the question of law considered in the previous case. The Court herein clearly differentiated between a human's work and something artificial. Justice Holmes, writing for the majority, delineated the uniqueness of human personality and stipulated the same as a prerequisite to a copyright. ${ }^{17}$ The Court made its stance clear by using the words 'something irreducible, which is one man's alone' which meant that there was no scope for anything that was not a product of man's creativity. ${ }^{18}$

\section{3 Alfred Bell \& Co. v. Catalda Fine Arts, Inc.}

This judgment witnessed a softer approach towards copyrights being adopted by the Courts. The Court lowered the standard for originality and held that the work to be original, it must not be copied from any other artistic work of similar character. ${ }^{19}$ It even held that unintentional or accidental variations may be claimed by an author as his or her own. This judgment therefore was a respite to people claiming copyrights for work generated by AIs as it wasn't copied, despite it being generated through certain programming and algorithms. These three judgments, to some extent, clear the ambiguity that prevails around grant of protection

${ }^{15}$ Burrow Gilles Lithographic v. Sarony, 111 U.S. 53 (1884).

16 Id.

${ }^{17}$ Bleistein v. Donaldson Lithographing Co., 188 U.S. 239 (1903).

18 Id.

${ }^{19}$ Alfred Bell \& Co. v. Catalda Fine Arts, Inc.,191 F.2d 99 (2d Cir. 1951). 
to AI systems. However, a lack of definitive stance still affects the prospective right holders.

\section{AI and Copyright Protection}

The ambiguity regarding the stance on $\mathrm{AI}$ is not recent and dates back to 1974, wherein the National Commission on New Technological Uses of Copyrighted Works (CONTU) in one of its report stated that, the development of an AI with the capacity of creating an independent work is theoretical and not practical. ${ }^{20}$ The Office of Technology Assessment (OTA) again revisited the issue in 1986 when it evaluated the implications of rapid advancements in interactive computing on IP. OTA disagreed with CONTU and suggested AIs be considered as legitimate co-authors of copyrighted works. $^{21}$ Thirty years from then, the debate surrounding AIs is at its prime, wherein one side argues the inability of computers to be as creative as humans, whereas the other disagrees on the pretext of defining creativity.22

One of the sharp critics against AIs being granted protection is, Lovelace. She states that a machine lacks creativity due to its rule bound behavior. The logic behind her theory being that, creativity is the ability to do the unpredictable, i.e., not following the usual routine, unlike something machines and computers always do. ${ }^{23}$ The same is countered by authors terming writers as machines themselves, as they process existing works and deduce most of their works from pre-existing ideas. For instance, there exist multiple copyrights on movies based on the premise of 'Romeo and Juliet'. Similar instances exist in the music industry too. ${ }^{24}$ They rely on judgments like Cummins v. Bond25, wherein the Court was faced

20 Final Report,NATIONAL COMMISSION ON NEW TECHNOLOGICAL UsES OF COPYRIGHTED WORKS 4 (1978), http:/ / eric.ed.gov/PDFS/ED160122.pdf.

21 Intellectual Property Rights in an Age of Electronics and Information, U.S. OfFICE OF TECHNOLOGICAL ASSESSMENT (1986), https:// www.princeton.edu/ ota/disk2/1986/8610/8610.PDF.

22 DAVID GelernTER, THE Muse In THE MACHINE 83 (Free Press, 1994).

${ }^{23} \mathrm{Id}$.

24 Charles Ames, Artificial Intelligence and Music Composition,THE AGE OF INTELLIGENT MACHINES, (Raymond Kurzweil ed., 1991).

${ }^{25}$ Cummins v. Bond, (1927) 1 Ch. 167. 
with an author inquiring whether a work can be registered in the name of Jesus. The Court held that, the non-human nature of the source of a work should not be a bar to copyright, regardless of any independent editorial judgment being exercised in the process. This judgment is stretched by the ones in favor of AIs, to include registration of the work done by $\mathrm{AI}$, which is also non-human in nature.

Even if countries admitted to granting copyrights to the works of an AI, the question of who gets that copyright remains cryptic and difficult to fathom. This is because the current status of law requires a legal personhood of a right holder, something which an AI lacks, unless its creator is granted that on its behalf. ${ }^{26}$ However, there does exist a loophole in the same, which is with respect to what happens if the AI system was a purchase, whether the copyright will be granted to the creator or the buyer. This answer lies in favor of the creator, in countries like England and New Zealand, where the copyright in works authored by AI is given to the programmer, through legal fiction. Legal backing to the same is provided in the form of expanding the definition of copyright, to include computer generated works (the ones that lack a human author, i.e., AIs). ${ }^{27}$ However, this still does not answer the above question. Another problem with the current system is the nature of criminal liability of AIs. When AI was created, no one envisaged the wonders it would achieve, and it would not be unusual to expect the same to increase such that, AIs become an independent entity altogether in the future. A pertinent question regarding possible criminal liability of an AI will then arise. ${ }^{28}$ If the current stance continues, it will be the creator who is liable, despite him lacking the mensrea or actusreus of such an act. Therefore, the

26 James Boyle, Endowed by their Creator? The Future of Constitutional Personhood, THE BROOKINGS Institution FutURE OF THE CONSTITUTION SERIES, 70 N.C. L. REV. 1231 (1992), http:// www.brookings.edu/ papers/ 2011/0309_personhood_boyle.aspx.

27 Copyright, Designs and Patents Act, § 178, 1988 (UK); Copyright Act, § 2, 1994 (New Zealand).

28 Prof. Gabriel Hallevy, AI v. IP-Criminal Liability for Intellectual Property IP Offenses of Artificial Intelligence AI Entities, ONO ACADEMIC COLLEGE,https:/ / papers.ssrn.com/sol3/papers.cfm?abstract_id=2691923. 
present position of AIs under IP law has certain loopholes. The author in the later part of the paper suggests possible measures to fix these loopholes.

\section{Patent Laws \& Artificial Intelligence}

The interaction between Patent laws and AI is increasing in today's technological world. As illustrated in the previous part of this paper, AI has been used extensively in order to simplify the execution of basic functions and primarily reduce human effort. At a quick glance, $\mathrm{AI}$ enabled systems come across as working in a fashion akin to simple calculators and such gadgets. However, it functions in a much more complicated manner. Today, AI enabled systems are equipped to perform tasks based on their own key learnings, creating the possibility of them inventing something. While this is a huge development from a technological standpoint, it poses new challenging questions from a legal standpoint, i.e., from the perspective of patent law. This part of the paper shall first examine the concept of patents, moving onto its interaction with AI systems, and ultimately explaining the dilemmas posed by this interaction.

\section{1 Patents \& the Current Law}

A patent can be understood as the exclusive right over an invention. This 'invention' has been understood to cover any product or process, which provides to users a novel way of performing a certain action, including that which offers a new solution to an existing technical problem. ${ }^{29}$ The holder of such a right is entitled by law to exclude others from making, selling, or even using the patented invention for a limited term. Therefore, it can be said that the right guaranteed in such an instance legitimizes the creation of a monopoly for the benefit of the original inventor. ${ }^{30}$ As established previously, AI enabled systems are equipped to perform functions and even create inventions, which ordinarily results as an outcome of the application of human cognitive

29 Patents, World InTEllectual Property ORganization, http:// www.wipo.int/patents/en/.

30 Patent Protection - UNHinnovation, UNIVERSITY OF NEW HAMPSHIRE, http://innovation.unh.edu/patent-protection. 
processes. In fact, these machines are producing results which could qualify as patentable inventions. ${ }^{31}$

Under U.S Patent Law, an 'inventor' is defined as an individual or a set of individuals who invented or discovered the subject matter of the invention. ${ }^{32}$ This eliminates any inference which supports the premise that legislative intention in the United States sought to include inventions or rather the possibility of inventions being made by anyone besides humans. ${ }^{33}$ However, with increasing involvement of the AI systems in invention processes, such questions demand legal perusal. Such perusal can be witnessed faintly in the attempt by the European Union to encourage nations to expand their national laws generally, to accommodate copyrightable works produced by computer and other devices, under the category of 'own intellectual creation.' 34 While this is a progressive step in the direction of acknowledging creativity exhibited by these systems, while producing poetry, artwork etc., due regard must also be paid to include inventions and application of patents by AI systems and robotics.

The European Parliamentary Committee has noted how, in a matter of a couple of decades, AI systems could surpass human intelligence in terms of performing functions, which uncontrolled, could pose challenges as to the manner in which these AI systems control and manage their own destiny. ${ }^{35}$ Attention to patent rights is required when speaking of AI systems due to the high level of

31 Liza Vertinsky \& Todd M. Rice, Thinking about Thinking Machines: Implications for Machine Inventors For Patent Law, B. U. J SCI. \& TECH L. 82 (2002), http://www.bu.edu/law/journals-archive/ scitech/ volume82/ vertinsky\&rice.pdf.

32 Consolidated Patent Laws, § 100 (f), U.S.C 35, https:// www.uspto.gov/web/offices/pac/mpep/consolidated_laws.pdf.

33 Jason Lohr, Artificial Intelligence drives new thinking on Patent rights, LIME GREEN IP,http://www.limegreenipnews.com/2016/07/artificialintelligence-drives-new-thinking-on-patent-rights/.

34 Draft Report with recommendations to the Commission on Civil Law Rules on Robotics, EUROPEAN PARLIAMENT (2014-2019), http:// www. europarl.europa.eu/sides/getDoc.do?pubRef=-//EP// NON SG M L\%2BCOMPARL\%2BPE-582.443\%2B01 \%2BDOC\%2 BPDF\% 2BV0 //EN. $35 \mathrm{Id}$. 
autonomy enjoyed by such systems. This autonomy, allows AI enabled systems to perform functions without any kind of significant human intervention. Therefore, this increasing functionality allows for these machines or programs to be employed at early research stages which can eventually lead to some kind of 'discovery' taking place on the basis of the machine's abilities. ${ }^{36}$ This brings forth the dilemma faced while thinking of how to protect such a 'discovery'.

A crucial factor for any invention to be granted a patent is, whether or not it can pass the patentability criteria satisfactorily. This calls for it to possess novelty, an inventive step, and be capable of industrial application. ${ }^{37}$ In the case of inventions by AI enabled systems/technologies, the biggest challenge toward obtaining of a patent is satisfying this three steps test. For indicating novelty, it becomes necessary for the invention to be different from whatever exists in the prior art. Generally, this requires a thorough perusal of the existing prior art by the inventor to successfully determine at the invention stage itself, whether or not his invention can be easily anticipated, or is an outcome of further research and a creative mental component. While an AI system will certainly have access to prior art, due to its overseeing human scientists feeding in information, is it truly independent, let alone capable to make a judgment on whether or not its invention can account for something novel? As to the question of an inventive step, if novelty itself is difficult to determine by the AI system, chances of making innovations on existing models or concepts which is not obvious to a person skilled in the art, is certainly more difficult to achieve. ${ }^{38} \mathrm{At}$ present, AI is usually fed with pre-existing objectives which they are programmed to achieve. The technology must first advance to equip these systems with a human-like intelligence so that judgment calls on new situations can be made by them. Furthermore, on perusal of cases on patentability of computer

\footnotetext{
36 Supra note 31.

37 The Patents Act, § 2(I), 1970 (India); The Patents Act, § 2(ja), 1970 (India); The Patents Act, § 2(ac), 1970 (India).

38 Ronald $\mathrm{Yu}$, Should an Artificial Intelligence be allowed to Get a Patent?RовонUв,http:/ / robohub.org/should-an-artificial-intelligence-beallowed-to-get-a-patent/.
} 
programs, etc., it can be noticed that, the Court has denied patents to programs simply because what they perform is mechanical rather than inventive. ${ }^{39}$ This is an important consideration, since AI is primarily running on computer programs devised to perform certain functions, subject to variations made by its human inventor. The forthcoming section shall shed light on this human/robot inventor dichotomy, which further highlights the difficulty in granting patents to programs invented by AI.

However, with countries like India removing their rigid requirement of only computer programs in conjunction with a novel hardware being eligible for a patent, ${ }^{40}$ if an AI enabled system created a software which can be used on generic machines, it would entail practical utility, perhaps in more than one industry, which allows satisfaction of the industrial application requirement within the patentability test. On a general note, current laws and guidelines need to be streamlined in a manner which may allow for inventions by AI to be granted patents. However, with several obstacles and confusions still existing over patentability and other aspects, deeper examination of the issues is required.

\section{2 Understanding the New Dimensions of 'Invention' \& 'Inventor'}

Invention, as seen, has many important elements, determining whether patent may be granted. However, there are certain requirements which are to be met when one is to be classified as an inventor. In the US, for instance, in the case of Townsend v. Smith ${ }^{41}$, it was held that, for something to be construed as a valid outcome of an invention, it must go through the stage of 'conception', i.e., a permanent idea must have been conceived in the mind of the

${ }^{39}$ Bilsk v. Kappos, 561 U.S. 593 (2010).

40 Office Order No. 36(2017), InTEllectual PROPERTY OfFICE (India), http:/ / www.ipindia.nic.in/writereaddata/Portal/Images/pdf/Office_Or der_No_36_of_2017_for_Revised_Guidelines_for_Examination_of_CRIs. pdf; BalajiSubramaniam, Patent Office Reboots CRI Guidelines Yet Again: Removes 'novel' Hardware Requirement, SPICYIP, https:// spicyip.com/ 2017/07/ patent-office-reboots-cri-guidelines-yet-again-removes-novelhardware-requirement.html.

41 Townsend v. Smith, 36 F.2d 292,293 (1929). 
inventor before the same be put into practice. If something is reduced not on account of a preconceived idea, then such a thing cannot be termed an invention and such person as a result is not an inventor. ${ }^{42}$ With such ideas of conception, it has been argued that such forms of creative conception can occur in the human mind alone. ${ }^{43}$ One of the most persuasive arguments for $\mathrm{AI}^{\prime}$ s inclusion in the category of 'inventor' is using the rationale behind the abolition of the 'flash of genius' patentability test. ${ }^{44}$ While this test honored the conception requirement for recognizing something as an invention, ${ }^{45}$ the US Congress negated this requirement and stated that, if an invention were something leading to the advancement of the science it wished to work upon, then the process of how it arose in the mind of the inventor, becomes irrelevant. ${ }^{46}$ Naturally, since several AI programs such as AlphaGo, Watson, etc. perform functions such as generating solutions based on massive influx of data, it may be argued that these solutions contribute to the advancement of such science and hence must be granted patent status. However, the situation according to scholars is not as straightforward.

Even if the argument of collaborative invention was to be used, which would acknowledge computers as inventors, along with their human counterparts, ${ }^{47}$ this does not stand because of the lack of 'legal personality' accorded to computers in most legal systems, akin to the position of corporations not being citizens. Another argument for allowing computers to be classified as inventors and afforded with patent protection is, the realization of the 'incentive theory'. While computers which are incapable of emoting may not use this as motivation, it will continue to incentivize humans to produce such technologies as they understand the benefits

\footnotetext{
$42 I d$.

43 Can a Computer Be an Inventor?,FENWICK \& WEST LLP, https:// casetext.com/case/townsend-v-smith/posts/can-a-computer-be-aninventor.

${ }^{44} \mathrm{Id}$.

${ }^{45}$ Cuno Engineering v. Automatic Devices, 314 U.S. 84 (1941).

46 Supra note 43.

47 Ryan Abbot, I think, therefore I Invent: Creative Computers and the Future of Patent Law, 57 B.C.L. Rev. 1079, 1095 (2016).
} 
emerging due to patent protection. ${ }^{48}$ However, patents are largely provided to protect the inventor and honor his attachment to the invention, which he does not wish to be used at an exponential rate by others. Due to this, opponents of patents protection being granted to AIs, argue that computers lack any such attachment. ${ }^{4}$ This makes them incapable of having strong opinions with regard to the manner of use of their invention, thereby defeating the very purpose behind a patent protection.

\section{3 The Way Forward}

There is no denying that $\mathrm{AI}$ is bound to develop increasingly by each passing day. With companies like GE, IBM, Apple, etc., advancing their attempts toward revolutionizing technologies related to providing software solutions, sophisticated technologies based on AI are bound to increase the number of such 'inventions' which may come about. There exists immense scope for legislators to develop guidelines in determining of such situations, providing it the most adequate form of legal safeguarding. However, the author shares the view of Stephen Hawking when he states that the autonomy of AI can diminish the worth of human thinking and invention. A more favorable solution would be to grant a more collaborative form of patent protection for the inventions made by an AI. This is because a human element is essential in managing the rights and obligations associated with patents, which cannot be done solely with a machine. Further, with increasing prospects of using thousands of AI enabled networks which function with or without human intervention, patent protection requires to be awarded on some anthropomorphic agent, who may be recognized in case such invention malfunctions, or causes a possible violation of law, therefore attracting criminal liability. It must be remembered that in the quest of making IP laws adaptable to the changing technologies, one cannot choose to create an imbalance by diminishing the desired effects of criminal laws, which necessarily survive on human elements being involved. Additionally, we cannot completely submit to AI technologies, which would possibly reduce the role of the human race itself.

${ }^{49} \mathrm{Id}$ at 1107. 


\section{Conclusion}

The current position of AIs under IP is problematic, wherein, recognition of work generated by AI is a step towards the future, but its implementation is the real problem. The authors suggest the following to help ameliorate the same.

\section{1 A Uniform Recognition for AIs.}

Despite AIs being a reality around the world, they only carry recognition in a select few countries like United States, ${ }^{50}$ England and New Zealand. ${ }^{51}$ A positive step towards the recognition of AIs could be that, all member countries of multilateral trading forums begin to recognize the same, for instance, in the form of an amendment to TRIPS.

\section{2 Passage of an Artificial Intelligence Data Protection Act}

The AIs today perform human-like functions in every sphere. It would not be amusing if, tomorrow they can perform functions better than humans and take their decisions themselves. To keep a track of the same, a legislation governing AIs should be drafted, namely the Artificial Intelligence Data Protection Act. ${ }^{52}$ The Act could include remedies for both criminal and civil offences committed by an AI to its human actors. The Act could also set up a regulatory framework to govern and adjudicate the acts of AIs and look into violations, if any, committed by them.

\section{3 Fixing the Lacunae in Criminal Liability of AIs' actions.}

Today, acts of an AI are copyrighted by its creator. Analogously if any criminal liability is to accrue, the same would be attributed to the creator too, who might not be aware of the action of the AI. Such a lacunae should be fixed, so as to provide a specific sanction for the AI, maybe in form of destruction of such an AI, or prohibition of the technology behind its creation from being used.

\footnotetext{
50 Supra note 8.

51 Supra note 27.

52 Artificial Intelligence Poses a Greater Risk to IP than Humans to, TECHCRUNCH(Dec. 31， 2015), https:// techcrunch.com/ 2015/ 12/31/artificial-intelligence-poses-a-greater-risk-to-ip-than-humans-do/.
} 
Tripathi and Ghatak Artificial Intelligence and Intellectual Property Law

This would be a major step to prevent innocent creators from being punished, who have no control over the actions of the AI.

VI. 4 Clearing the Ambiguity with regard to Application of Patent laws.

While there is a clear demarcation between the inventor and the invention, with the advent of AI systems it is essential that legislators address the question of inclusion of AI enabled systems under this category. With the increasing usage of these technologies and the widespread expanse of the solutions generated by the same, protection as an issue becomes an integral question. Questions of incentivizing human scientists to create more of such systems alongside the danger of granting complete autonomy to these super intelligent systems is an area wherein the need for proper guidelines is most urgent. 